\title{
Biosynthesis lipase from the fungus Penicillium hordei isolated from waste fat
}

\author{
Daniil Beliaev ${ }^{1}$, Mikhail Pushkarev ${ }^{1, *}$, Grigorii Kozlov ${ }^{1}$, Igor Ryabinin ${ }^{2}$, \\ and Alexander Mishin ${ }^{1}$ \\ ${ }^{1}$ Saint-Petersburg State Institute of Technology, 190013, 26 Moskovsky prospect, St. Petersburg, \\ Russia \\ ${ }^{2}$ Kashkin Research Institute of Medical Mycology, North-Western State Medical University named \\ after I.I. Mechnikov, 194291, 1/28 Santiago de Cuba street, St. Petersburg, Russia
}

\begin{abstract}
The article provides a method of isolating a lipase producer and identification methods by classical methods in microbiology of an isolated micromycete producing lipase. The species affiliation of Penicillium hordei has been determined. The temperature of micromycete cultivation was studied, as well as the dynamics of Penicillium hordei lipase biosynthesis. Screening plans were also carried out (Plackett-Berman Plan), then optimization according to the steep climb plan and an experiment based on the plan of a full-factor experiment (three-level CFE) was also conducted to determine the optimal concentrations that are significant for lipase biosynthesis of components. A mathematical model is constructed that describes the relationship between the influence of two significant factors on the volumetric activity of $P$. Hordei culture fluid. The most optimal composition for the culture fluid for lipase biosynthesis, Penicillium hordei micromycete, was compiled.
\end{abstract}

\section{Introduction}

Urban automobile transport on internal combustion engines (especially diesel) has recently become an object of intense criticism due to emissions and, in many, primarily European countries, the process of banning and replacing it with electric cars, as well as the replacement of mineral oil with biofuels and natural gas. Each of the directions has its advantages and problems, however, the problem of minimizing costs is common, the biodiesel industry is no exception. An important way to reduce the cost of producing biodiesel is the application of oil and fat waste as a raw material [1], as well as effective and environmentally friendly biocatalysts specific to the triglycerides contained in this waste [2]. In this regard, the search for new producers of highly active lipases and the improvement of their purification methods for fuel and natural gas are relevant [3].

In the course of the study a culture showing high lipolytic activity was isolated from fatty waste from meat processing affected by molds, its identification was carried out, and the nutrient medium was optimized to obtain maximum activity.

\footnotetext{
${ }^{*}$ Corresponding author: malexpush@bk.ru
} 


\section{Materials and Methods}

\subsection{Microbiological studies}

Classical methods were used to isolate micromycetes; the studied samples of food products were sown on a nutrient medium with rhodamine vegetable oil (sunflower oil) - $25 \mathrm{~g} / \mathrm{l}$, peptone - $3 \mathrm{~g} / \mathrm{l}$, yeast extract - $1 \mathrm{~g} / \mathrm{l}, \mathrm{NH}_{4} \mathrm{NO}_{3}-1 \mathrm{~g} / \mathrm{l}, \mathrm{KH}_{2} \mathrm{PO}_{4}-0,7 \mathrm{~g} / \mathrm{l}, \mathrm{K}_{2} \mathrm{HPO}_{4}-0,3 \mathrm{~g} / \mathrm{l}$, $\mathrm{MgSO}_{4}$ x $7 \mathrm{H}_{2} \mathrm{O}-0,1 \mathrm{~g} / 1, \mathrm{CaCl}_{2}-0,2 \mathrm{~g} / 1, \mathrm{FeSO}_{4}-0,01 \mathrm{~g} / 1$, Triton X-100 - 0,1 g/l, agar agar $20 \mathrm{~g} / \mathrm{l}$, rhodamine $\mathrm{B}-0,01 \mathrm{~g} / \mathrm{l}$.

Species-level identification of the isolated micromycete culture was carried out with using "Aspergillus \& Penicillium Database" electronic system of Westerdijk Fungal Biodiversity Institute (Utrech, Netherlands) [4]. For this purpose the strain from working collection was subcultured on Czapek agar (classic formula), Czapek yeast autolysate agar and Sabouraud maltose agar in Emmons' modification (as a substitution of malt extract agar).

The microbiological culture media formulations described in the Atlas R.M. manual were used as the base ones. [5]. The passages were carried out by the three-point method with incubation for 7 days at $25^{\circ} \mathrm{C}$. At the end of the incubation period photofixation of the growth results (Presto T55 camera, Rekam, Canada), microscopy of the colonies' fragments in wet mount preparations, microphotography, and micrometry (Leica DM LB2 microscope with a DFC320 camera, Leica, Germany) were done. Digital micrometry was performed in GIMP 2.8.6 image editor which in combination with XnView 2.35 was used for pre-print images preparing.

To identify the strain the following parameters were determined: lengths of phialids, metulae and conidiophores; diameter of the conidia; features of the conidia surface; width of the conidipphores; conifiophores branching pattern; fact of convergence or divergence of the conidiogenous elements; presence of hyphal strands on malt-agar-like medium; texture of colonies on malt-agar-like; conidial pigment and color of colonial reversum on Czapek yeast autolysate medium; the structure of the conidial apparatus.

\subsection{Study of the cultivation temperature of Penicillium hordei}

To determine the optimal temperature of culture growth, the diameter of the colonies was measured on dense agarized media at the following temperatures: $25^{\circ} \mathrm{C}, 30^{\circ} \mathrm{C}, 35^{\circ} \mathrm{C}, 40^{\circ} \mathrm{C}$, $45^{\circ} \mathrm{C}$ during 9 days. The composition of the nutrient medium: vegetable oil (sunflower oil) 25 g/l, peptone - 3 g/l, yeast extract - 1 g/l, NH4NO3 - 1 g/l, KH2PO4 - 0,7 g/1, K2HPO4 - 0,3 g/l, MgSO 4 x 7 H2O - 0,1 g/l, CaCl2 - 0,2 g/1, FeSO4 - 0,01 g/l, Triton X-100 - 0,1 g/l, agar agar $-20 \mathrm{~g} / \mathrm{l}$, rhodamine $\mathrm{B}-0,01 \mathrm{~g} / \mathrm{l}$.

\subsection{The study of the dynamics of the biosynthesis of lipase Penicillium hordei}

Determination of the maximum lipolytic activity was carried out on a selective liquid medium by an in-depth method for 6 days. Every day lipolytic activity was measured in the selected samples. Cultivation took place in $750 \mathrm{ml}$ flasks with a medium volume of $100 \mathrm{ml}$. The rotation speed of the rocking chair was $230 \mathrm{~min}-1$. Cultivation took place at a temperature of $25^{\circ} \mathrm{C}$. The composition of the nutrient medium: vegetable oil (sunflower oil) - $25 \mathrm{~g} / \mathrm{l}$, peptone - $3 \mathrm{~g} / \mathrm{l}$, yeast extract - $1 \mathrm{~g} / \mathrm{l}, \mathrm{NH}_{4} \mathrm{NO}_{3}-1 \mathrm{~g} / \mathrm{l}, \mathrm{KH}_{2} \mathrm{PO}_{4}-0,7 \mathrm{~g} / 1, \mathrm{~K}_{2} \mathrm{HPO}_{4}-0,3$ $\mathrm{g} / \mathrm{l}, \mathrm{MgSO}_{4} \times \mathrm{H}_{2} \mathrm{O}-0,1 \mathrm{~g} / \mathrm{l}, \mathrm{CaCl}_{2}-0,2 \mathrm{~g} / 1, \mathrm{FeSO}_{4}-0,01 \mathrm{~g} / \mathrm{l}$, Triton X-100 - 0,1 g/l, agar agar $-20 \mathrm{~g} / \mathrm{l}$, rhodamine $\mathrm{B}-0,01 \mathrm{~g} / \mathrm{l} .10 \mathrm{ml}$ of water was added to the test tube with the culture on sloping agar, then the necessary manipulations were performed to form a suspension, following that this suspension was transferred by washing to Erlenmeyer flasks. 
$5 \mathrm{ml}$ of suspension were added per $100 \mathrm{ml}$ of culture medium. Determination of lipolytic activity was analyze by hydrolysis of 4-nitrophenyl palmitate [6].

\subsection{Method for determination of lipolytic activity}

The essence of the method is to determine the activity of (U) lipases as the number of micromoles of 4-nitrophenol cleaved during hydrolysis of 4-nitrophenyl palmitate in $1 \mathrm{~min}$ at $30^{\circ} \mathrm{C}$. The optical density of the solutions was measured on a KFK-3 photometer at a wavelength of $410 \pm 3 \mathrm{~nm}$. The concentration of the substance in the test solution was determined by the calibration graph. The culture fluid was filtered on a Schott filter to remove mycelium, following that lipolytic activity was analyze. [6].

\subsection{Optimization of the composition of the nutrient medium for the producer of lipase Penicillium hordei}

\section{Experiment planning}

The composition of the nutrient media was optimized in three stages: the first stage is a screening experiment (Plackett-Berman plan) [7], the second stage is optimization of the composition using the steep climb method [8]; the third stage is an experiment based on a full-factor experiment design [9] to describe the optimum region. All calculations were carried out using the STATISTICA application software package. The confidence level was taken equal to $95 \%$ [6].

As the initial composition of the nutrient medium was taken medium containing 10 components (composition see table 1 No. 13). To assess the effects of the concentrations of these components on lipase production by the Penicillium hordei culture, an experiment was performed in accordance with the Plaketta-Berman plan (Table 1).

Culture media were seeded, see paragraph 2.3.

Table 1. The concentration of the components of the nutrient media in $\mathrm{g} / \mathrm{l}$ for the fractional factorial experiment according to the Plackett-Berman method

\begin{tabular}{|c|c|c|c|c|c|c|c|c|c|c|}
\hline 익 & $\overline{0}$ & 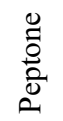 & 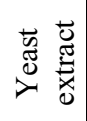 & 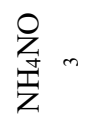 & 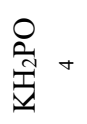 & 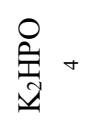 & $\begin{array}{l}0 \\
\mathbb{D}^{+} \\
\sum^{\infty}\end{array}$ & $\underset{\tilde{U}}{\tilde{U}}$ & $\begin{array}{l}0 \\
0 \\
0 \\
1\end{array}$ & 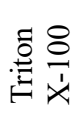 \\
\hline 1 & 30 & 2 & 2 & 0 & 0.4 & 0.1 & 0.2 & 0.4 & 0.02 & 0.0 \\
\hline 2 & 30 & 4 & 0 & 2 & 0.4 & 0.1 & 0.0 & 0.4 & 0.02 & 0.2 \\
\hline 3 & 20 & 4 & 2 & 0 & 1.0 & 0.1 & 0.0 & 0.0 & 0.02 & 0.2 \\
\hline 4 & 30 & 2 & 2 & 2 & 0.4 & 0.5 & 0.0 & 0.0 & 0.00 & 0.2 \\
\hline 5 & 30 & 4 & 0 & 2 & 1.0 & 0.1 & 0.2 & 0.0 & 0.00 & 0.0 \\
\hline 6 & 30 & 4 & 2 & 0 & 1.0 & 0.5 & 0.0 & 0.4 & 0.00 & 0.0 \\
\hline 7 & 20 & 4 & 2 & 2 & 0.4 & 0.5 & 0.2 & 0.0 & 0.02 & 0.0 \\
\hline 8 & 20 & 2 & 2 & 2 & 1.0 & 0.1 & 0.2 & 0.4 & 0.00 & 0.2 \\
\hline 9 & 20 & 2 & 0 & 2 & 1.0 & 0.5 & 0.0 & 0.4 & 0.02 & 0.0 \\
\hline 10 & 30 & 2 & 0 & 0 & 1.0 & 0.5 & 0.2 & 0.0 & 0.02 & 0.2 \\
\hline 11 & 20 & 4 & 0 & 0 & 0.4 & 0.5 & 0.2 & 0.4 & 0.00 & 0.2 \\
\hline 12 & 20 & 2 & 0 & 0 & 0.4 & 0.1 & 0.0 & 0.0 & 0.00 & 0.0 \\
\hline 13 & 25 & 3 & 1 & 1 & 0.7 & 0.3 & 0.1 & 0.2 & 0.01 & 0.1 \\
\hline
\end{tabular}

The selected significant factors at the next stage of optimization of the composition of the nutrient medium were varied using the steep gradient ascension method [8]. The steep ascent 
trajectory was determined by the linear model obtained on the basis of a full-factor experiment. Table 4 . Table 5 presents the experimental plan, compiled in accordance with the steep gradient climb method.

At the third stage, the components of the nutrient medium, previously selected as the most significant, varied in accordance with the plan of the three-level full-factor experiment (Table $6)$.

In accordance with the plans (tables $1,5,6,7)$ liquid nutrient media were prepared. The media was autoclaved at an overpressure of $71 \mathrm{kPa}$ for 30 minutes.

To prepare the seed for the deep cultivation process, the Penicillium hordei strain was grown in test tubes on mowed agar in Saburo medium at a temperature of $25^{\circ} \mathrm{C}$. Cultivation was carried out until the agar surface was completely overgrown for 3 days. The biomass was transferred by flushing in accordance with paragraph 2.3 of the Erlenmeyer flask with a liquid nutrient medium and cultivated for 6 days at a temperature of $25^{\circ} \mathrm{C} .5 \mathrm{ml}$ of inoculum was introduced per $100 \mathrm{ml}$ of the nutrient medium.

Deep cultivation was carried out in $0.75 \mathrm{~L}$ Erlenmeyer flasks with $100 \mathrm{ml}$ of medium on a rotary shaker (rotation speed $230 \mathrm{~min}^{-1}$ ) at $25^{\circ} \mathrm{C}$ for 6 days.

The biomass was separated from the culture fluid by filtration. The activity of lipolytic enzymes was determined in the obtained supernatant.

\section{The results and discussion}

\subsection{Isolation and identification of micromycete}

The culture was isolated from samples of melted pork fat stored in a refrigerator at $+5^{\circ} \mathrm{C}$ and having obvious signs of biodeterioration on rhodamine-containing medium.

The macro- and microscopic parameters of the studied strain are shown in Table 1, Figures 2 and 3. Measures of the strain identification made it possible to determine the isolated culture as Penicillium hordei Stolk, 1969. Earlier, cultures of this species were isolated from cereals, in particular from barley (Hordeum sativum, the studied species got its own name from this plant) and sometimes from the soil $[10,11,12]$.

This culture is generally similar to typical descriptions of the species and section Corymbifera [10, 11], but has some individual characteristics. On Czapek agar medium the colonies produce spores rather intensively, but in a mature state of culture without shades of yellow on the front side, the exudate is not red or orange, but light yellow.

Cynnemas (bundles, funiculi) consisting of conidiophores in the culture are not explicitly traced, but meaning the fact that individual conidiophores in micropreparations are found sporadically, and "conidial brushes" are often densly confused in groups, sporulation of the studied strain occurs in short bundles that are tightly connected with the stroma of colonies.

Conidia, even when using the maximum magnification, appear smooth, only occasionally when the microiscrew is defocused, a slight unevenness of the cell wall is visible. Conidiogenous "brushes" in the culture are quite polymorphic, their elements are often converging (adpressed), but sometimes "spread out" (divaricate). 

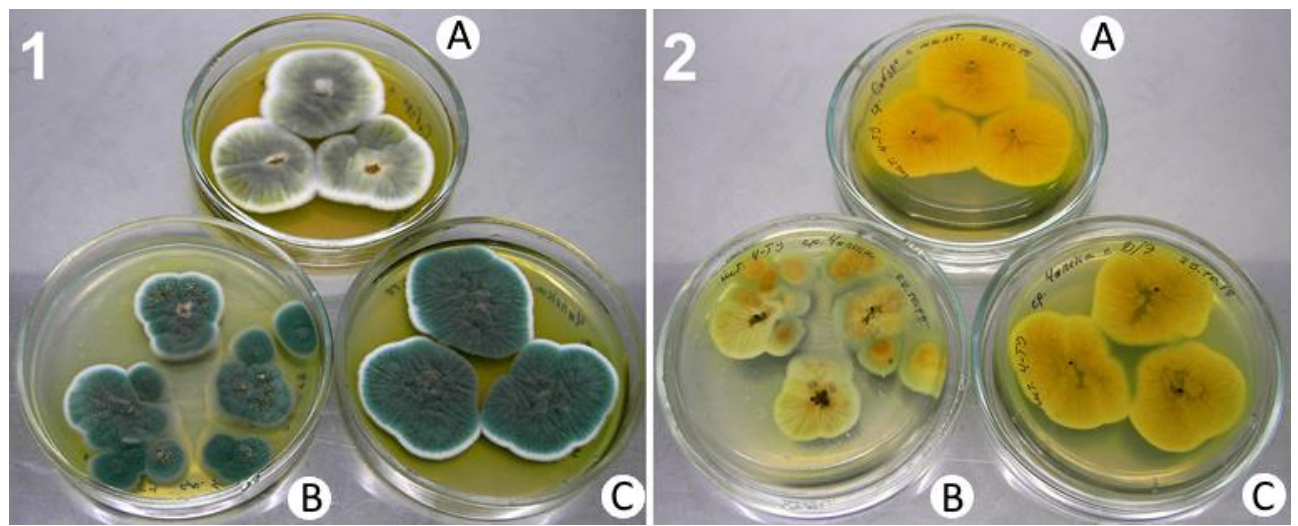

A - modified Sabouraud maltose agar;

B - classical Czapek medium;

C - Czapek yeast automate agar; 1 - "front" side, 2 - back side)

Fig. 1. Growth of $P$. hordei culture on nutrient media.

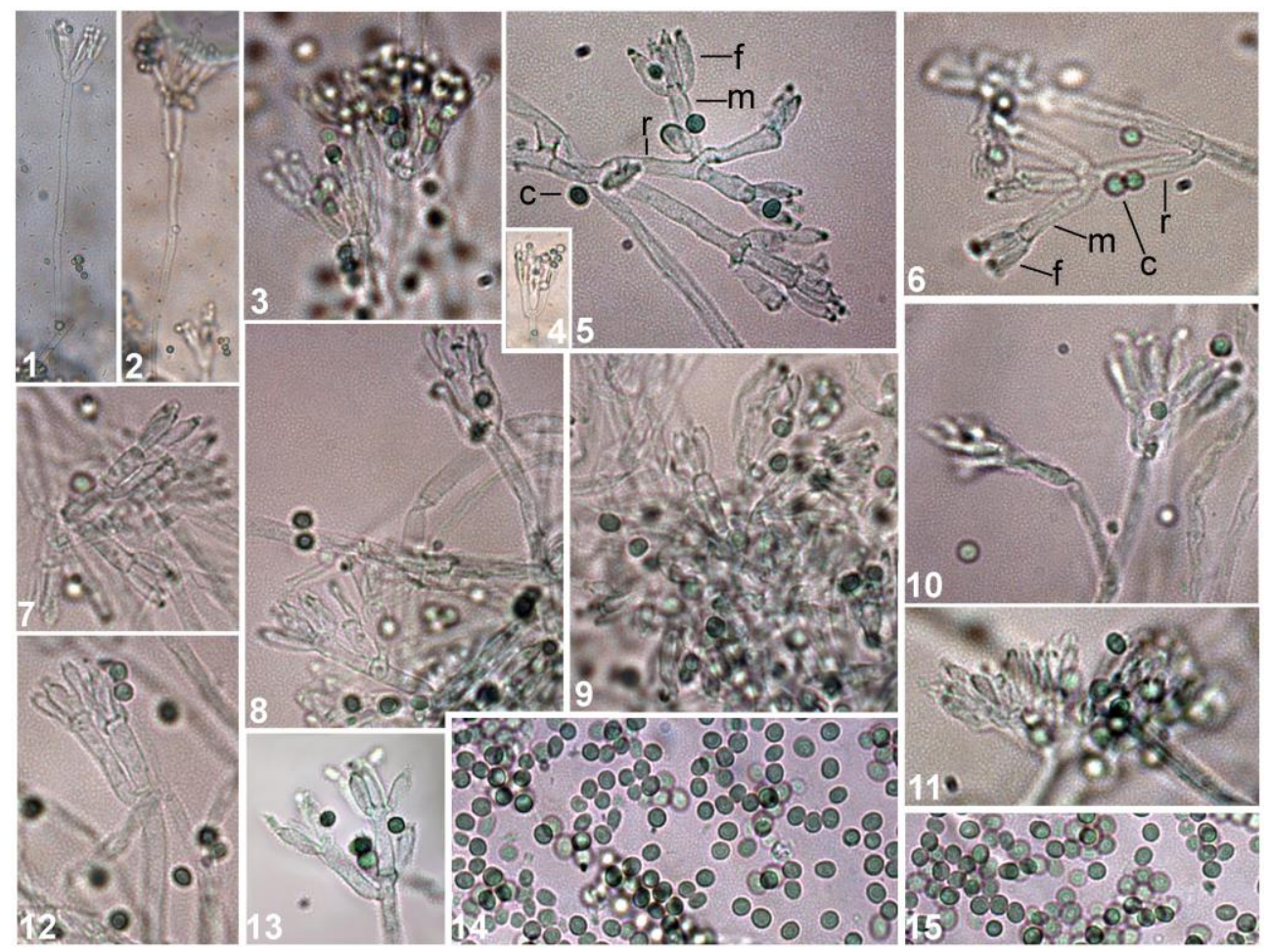

1, 2 - conidiophores; 3-13 - conidiogenous "brushes" (f - phialida, m - metula, $\mathrm{r}$ - branch, c - conidia; 5 - atypical divaricate "brush"; 9 - group of "brushes", apparently, emerging from the cynnema); 14, 15 - conidia. Magnification: 1, 2, 4 - x400; 3, 5-15 - x1000 (oil immersion).

Fig. 2. Micromorphology of the $P$. hordei strain in the Czapek yeast autolysate agar. 
Table 2. Morphological characteristics of the culture of the studied micromycete

\begin{tabular}{|l|c|}
\hline \multicolumn{1}{|c|}{ Parameter } & Meaning of parameter \\
\hline The length of the phialide, $\mu \mathrm{m}$ & $\approx 8.4$ \\
\hline The length of the metula, $\mu \mathrm{m}$ & $\approx 11.5$ \\
\hline Diameter of conidia, $\mu \mathrm{m}$ & $\approx 3.2$ \\
\hline Width of conidiophores, $\mu \mathrm{m}$ & $\approx 3.2$ \\
\hline The surface features of the conidia & $\begin{array}{c}\text { Predominantly smooth to } \\
\text { slightly noticeable }\end{array}$ \\
\hline Conidiophores (conidiogenous "brush") branching pattern & biverticillata, terverticillata \\
\hline Convergence / divergence of conidiodenous "brush" elements & adpressed (rarely splayed) \\
\hline The presence of hyphal strands (funiculi) in malt-agar-like medium & Not distinct \\
\hline Colonial texture on malt-agar-like medium & Felt \\
\hline Color of the reversum on Czapek yeast autolysate agar & uncolored (yellowish) \\
\hline Conidia pigment on Czapek yeast autolysate agar & dark brownish-green \\
\hline Colony diameter on Czapek yeast autolysate agar, mm & Up to 45 \\
\hline Colony diameter on classical Czapek agar colony, mm & Up to 29 \\
\hline Colony diameter on malt-agar-like medium, mm & Up to 27 \\
\hline
\end{tabular}

\section{2 study of the temperature and time of cultivation of Penicillium hordei}

Next, the optimal growth temperature of the culture was determined. The following temperatures were selected: $25^{\circ} \mathrm{C}, 30^{\circ} \mathrm{C}, 35^{\circ} \mathrm{C}, 40^{\circ} \mathrm{C}, 45^{\circ} \mathrm{C}$. The culture showed growth only at $25^{\circ} \mathrm{C}$ and $30^{\circ} \mathrm{C}$. At these temperatures, the culture growth rate was subsequently determined.

Comparing the growth rates at $25^{\circ} \mathrm{C}$ and $30^{\circ} \mathrm{C}$, the temperature of $25^{\circ} \mathrm{C}$ was higher and further $25^{\circ} \mathrm{C}$ was used to select the components of the nutrient medium for this $P$. hordei strain.

This temperature was adopted for further study of the dynamics of liposome biosynthesis of $P$. hordei in liquid nutrient media; for composition, see table 1 (No. 13). Table 3 presents the results of the study.

Table 3. The lipase activity on the time of cultivation

\begin{tabular}{|c|c|}
\hline Day of cultivation & Activity $* 10^{6}, \mathrm{U} / \mathrm{ml}$ \\
\hline 1 & 0 \\
\hline 2 & 0 \\
\hline 3 & 0.028 \\
\hline 4 & 0.52 \\
\hline 5 & 1.16 \\
\hline 6 & 1.37 \\
\hline
\end{tabular}

Up to the fifth day of cultivation, a strong turbidity was observed in the samples, indicating a high concentration of oil not processed by the lipase producer. Samples taken on the fifth and sixth days do not show turbidity.

\subsection{Optimization of the composition of the nutrient medium of the $P$. hordei lipase producer}

The first stage of the study was the screening of factors (components of the nutrient medium), the influence of which on the lipolytic activity of the culture fluid is insignificant. To do this, we used the mathematical design of the Plackett-Berman experiment, which allows you to test the largest number of main effects with the least number of observations. During the 
experiment, 13 compositions of nutrient media were prepared; in total, 10 parameters varied (table 1). The experimental results are shown in table 4.

Table 4. Volumetric activity of culture liquids $P$. hordei when cultured on nutrient media according to the Plaketta-Berman plan (in triplicate)

\begin{tabular}{|c|c|c|c|c|}
\hline & \multicolumn{4}{|c|}{ Activity * $10^{6},(\mathrm{U} / \mathrm{ml})$} \\
\hline medium number & 1 & 2 & 3 & Mean \\
\hline 1 & 0.47 & 0.52 & 0.47 & 0.49 \\
\hline 2 & 0.82 & 0.87 & 0.72 & 0.80 \\
\hline 3 & 0.74 & 0.77 & 0.04 & 0.52 \\
\hline 4 & 0.90 & 0.97 & 0.99 & 0.95 \\
\hline 5 & 0.55 & 0.57 & 0.62 & 0.58 \\
\hline 6 & 4.10 & 0.02 & 0.27 & 1.46 \\
\hline 7 & 1.10 & 1.12 & 0.89 & 1.04 \\
\hline 8 & 1.12 & 1.04 & 1.10 & 1.09 \\
\hline 9 & 1.059 & 1.00 & 1.02 & 1.03 \\
\hline 10 & 1.44 & 1.51 & 1.20 & 1.38 \\
\hline 11 & 0.37 & 0.29 & 0.33 & 0.33 \\
\hline 12 & 0.80 & 0.76 & 2.34 & 1.30 \\
\hline 13 & 1.45 & 1.39 & 1.50 & 1.45 \\
\hline
\end{tabular}

Based on the experimental results obtained according to the Plackett-Berman plan, the most significant components of the nutrient medium affecting lipase biosynthesis by the Penicillium hordei culture were identified. Factors were ranked according to a standardized assessment of effects (the Pareto diagram is presented in Figure 3). The vertical line indicates what the effect should be in magnitude in order to be statistically significant at a significance level of $\mathrm{p}=0.05$. 


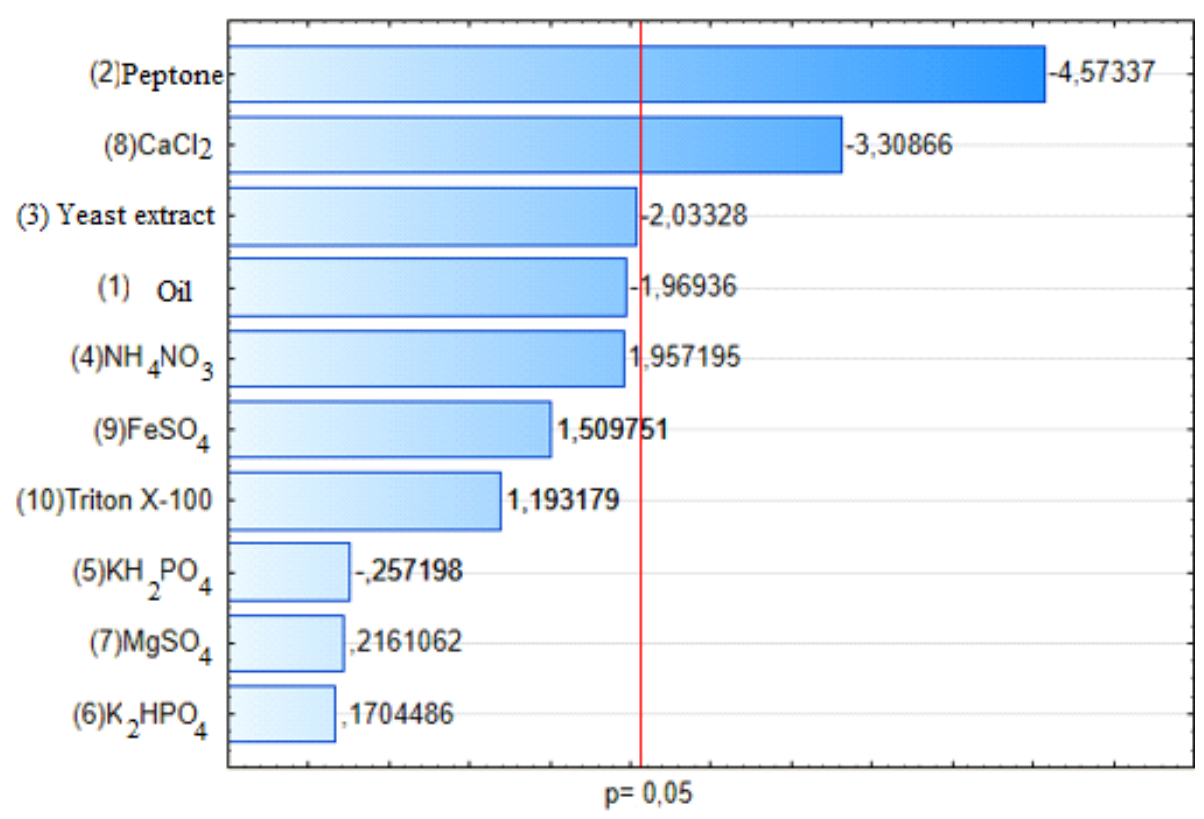

Fig. 3. Pareto diagram for strain $P$. hordei

The most significant factors statistically significantly affecting the biosynthesis of $P$. hordei lipase: the concentration of peptone and $\mathrm{CaCl} 2$. To further optimize the composition, these factors were used, as well as the oil concentration (as a lipase inducer), despite the absence of a proven effect.

Next, optimization was carried out according to the Box-Wilson method and a steep ascent along the surface of the gradient of the response function. To do this, an experiment was set up on the basis of a full factorial experiment (CFE) plan (the plan and results are shown in Table 5).

Table 5. The Plan and the results of CFE

\begin{tabular}{|c|c|c|c|c|c|}
\hline & \multirow{2}{*}{ Oil, $\mathrm{g} / \mathrm{i}$} & \multirow{2}{*}{ Peptone, $\mathrm{g} / \mathrm{l}$} & \multirow{2}{*}{$\mathrm{CaCl}_{2}, \mathrm{~g} / \mathrm{l}$} & \multicolumn{2}{|c|}{ Activity * $10^{6}, \mathrm{U} / \mathrm{ml}$} \\
\cline { 5 - 6 } & & & & 1 & 2 \\
\hline 1 & 25.0 & 1.0 & 0.1 & 0.47 & 0.55 \\
\hline 2 & 35.0 & 1.0 & 0.1 & 0.45 & 0.51 \\
\hline 3 & 25.0 & 3.0 & 0.1 & 0.88 & 0.98 \\
\hline 4 & 35.0 & 3.0 & 0.1 & 0.89 & 0.94 \\
\hline 5 & 25.0 & 1.0 & 0.3 & 0.47 & 0.48 \\
\hline 6 & 35.0 & 1.0 & 0.3 & 0.82 & 0.90 \\
\hline 7 & 25.0 & 3.0 & 0.3 & 1.61 & 1.57 \\
\hline 8 & 35.0 & 3.0 & 0.3 & 1.63 & 1.61 \\
\hline $9(\mathrm{c})$ & 30.0 & 2.0 & 0.2 & 0.73 & 0.75 \\
\hline
\end{tabular}

Next, the regression coefficients of the equation of the function were obtained and a new mathematical model was constructed (1). The determination coefficient (R2) for this mathematical model is 0.98 . It follows that the explained variable is exactly described by the 
model in question. The adjusted coefficient of determination is 0.82 and confirms that this model is suitable for further use in the search for the optimum region.

$$
\mathrm{y}=0,2394-0,0049 * X 1+0,0508 * X 2-0,1181 * X 3
$$

On the basis of the linear model (1), the steep ascent trajectory was calculated and 10 experiments were carried out with different quantitative compositions of the components Oil, Peptone, $\mathrm{CaCl}$. The experimental results are shown in table 6 .

Table 6. Component composition and PFE results for the steep climb method

\begin{tabular}{|c|c|c|c|c|c|}
\hline & \multirow{2}{*}{ Oil, g/l } & \multirow{2}{*}{$\begin{array}{c}\text { Peptone, } \\
\mathrm{g} / \mathrm{l}\end{array}$} & \multirow{2}{*}{$\mathrm{CaCl}_{2}, \mathrm{~g} / \mathrm{l}$} & \multicolumn{2}{|c|}{ Activity * $10^{6}, \mathrm{U} / \mathrm{ml}$} \\
\cline { 5 - 6 } & & 2.0 & 0.2 & 1 & 2 \\
\hline $1(\mathrm{c})$ & 30.0 & 0.1 & 0.73 & 0.75 \\
\hline 2 & 29.7 & 2.5 & 0.1 & 1.12 & 0.88 \\
\hline 3 & 29.4 & 3.0 & 0.1 & 1.27 & 1.05 \\
\hline 4 & 29.1 & 3.5 & 0.1 & 1.39 & 1.21 \\
\hline 5 & 28.8 & 4.0 & 0.1 & 1.58 & 1.43 \\
\hline 6 & 28.5 & 4.5 & 0.1 & 1.76 & 1.67 \\
\hline 7 & 28.2 & 5.0 & 0.1 & 1.90 & 1.93 \\
\hline 8 & 27.9 & 5.5 & 0.1 & 1.78 & 1.74 \\
\hline 9 & 27.6 & 6.0 & 0.1 & 1.67 & 1.59 \\
\hline 10 & 27.3 & 6.5 & 0.1 & & 1.1 \\
\hline
\end{tabular}

After analyzing the experimental data, we can conclude that the optimum region is between at points $7-9$.

The final stage of optimization is the study of the optimum region, for which a three-level CFE has been compiled (table 7).

Table 7. The results of the CFE for the study of the optimum area

\begin{tabular}{|c|c|c|c|}
\hline & Oil, $\mathrm{g} / \mathrm{l}$ & Peptone, $\mathrm{g} / \mathrm{l}$ & $\begin{array}{c}\text { Activity*10 } \\
\mathrm{U} / \mathrm{ml}\end{array}$ \\
\hline 1 & 27.5 & 5.0 & 1.922 \\
\hline 2 & 27.5 & 6.0 & 1.973 \\
\hline 3 & 28.5 & 5.0 & 1.910 \\
\hline 4 & 28.5 & 6.0 & 1.941 \\
\hline 5 & 27.3 & 5.5 & 2.275 \\
\hline 6 & 28.7 & 5.5 & 1.898 \\
\hline 7 & 28.0 & 4.8 & 1.863 \\
\hline 8 & 28.0 & 6.2 & 2.031 \\
\hline $9(\mathrm{C})$ & 28.0 & 5.5 & 2.039 \\
\hline $10(\mathrm{C})$ & 28.0 & 5.50 & 2.098 \\
\hline
\end{tabular}

Based on the results of the experiment, a mathematical model was constructed (2) describing the relationship of the influence of two factors on the activity of the culture fluid $P$. hordei

$$
Y=-10,8393+0,6348 * X_{I}-0,0115 * X_{I}^{2}+1,0680 * X_{2}-0,0825 * X_{2}^{2}-0,005 * X_{1} * X_{2}
$$

Figure 4 shows the visualization of the mathematical model (2). 


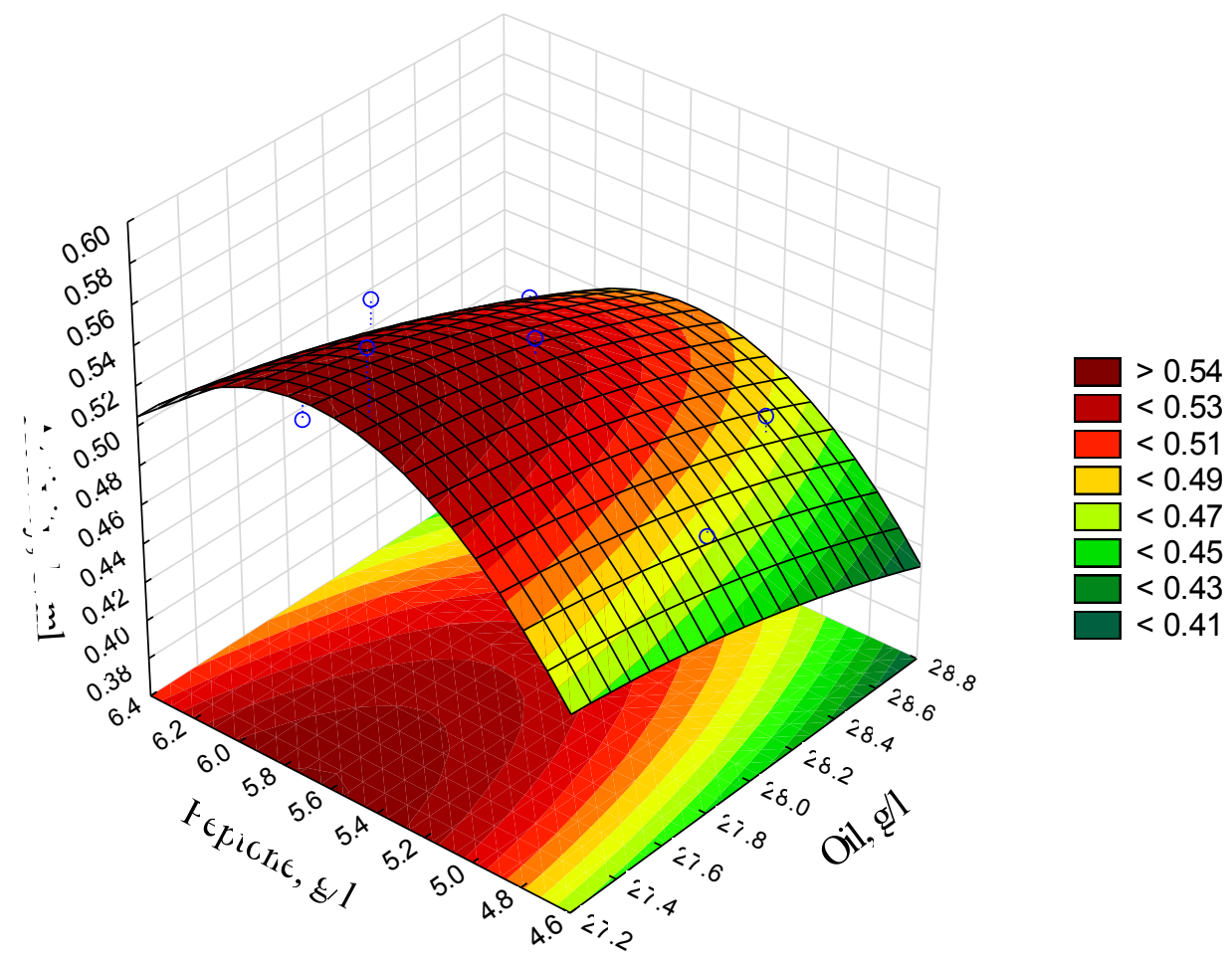

Fig. 4. Graph of the surface of the response function.

\section{Conclusion}

Penicillium hordei lipase producer was isolated and identified from waste fat. Using a screening experiment according to the Plackett-Berman plan, steep ascent along the response surface, and an experiment based on the three-level Box-Bencken second-order plan to describe the optimum region, the composition of the medium was optimized. A lipolytic activity of the culture fluid of $2.275 * 10^{-6} \mathrm{U} / \mathrm{ml}$ was achieved.

This work was supported by the state mission of the Ministry of Science and Higher Education of the Russian Federation (785.00.X6019).

\section{References}

1. A.K. Singh, M. Mukhopadhyay, Overview of fungal lipase: a review. Applied biochemistry and biotechnology 166(2), 486-520 (2012).

2. V.A. Galynkin, A.V. Garabadzhiu, A.H. Enikeev, M.M. Karasev, G.V. Kozlov, Marine biological resources: An advanced raw material base for biofuel. Catalysis in Industry 3(1), 57-61 (2011). 
3. E.R. Yagmurov, G.V. Kozlov, M.A. Pushkarev, Lipase purification: the review of conventional and novel methods. Journal of Hygienic Engineering and Design 20, 60-69 (2017).

4. Aspergillus \& Penicillium Database. Polyphasic identification. Westerdijk Fungal Biodiversity Institute. http://www.wi.knaw.nl/Aspergillus/Biolomicsid.aspx

5. R.M.Atlas, Handbook of Microbiological Media (CRC Press, 2004).

6. M.A. Pushkarev, A.V. Garabadzhiu, D.Y. Beliaev, O.G. Timofeeva, S.E. Smirnova, Optimization of culture medium composition for lipase production by Bacillus thuringiensis, FES: Finance. Economy. Strategy 15(10), 64-70 (2018).

7. R.L. Plackett, J.P. Burman, The design of optimum multifactorial experiments. Biometrika 33(4), 305-325 (1946).

8. H. Eschenauer, J. Koski, A. Osyczka (eds.), Multicriteria design optimization: procedures and applications (Springer Science \& Business Media, 2012).

9. G.E. Box,. D.W. Behnken, Some new three level designs for the study of quantitative variables. Technometrics 2(4), 455-475 (1960).

10. R.A. Samson, A.C. Stolk, R. Hadlok, Revision of the subsection Fasciculata of Penicillium and some allied species. Studies in Mycology 11, 1-47 (1976).

11. J.C. Frisvad, R.A. Samson, Polyphasic taxonomy of Penicillium subgenus Penicillium. A guide to identification of food and air-borne terverticillate Penicillia and their mycotoxins. Studies in mycology 49(1), 1-174 (2004).

12. T.K. Kolanlarli, A. Asan, B. Sen, S. Okten, Biodiversity of Penicillium species isolated from Edirne Söğütlük Forest soil (Turkey). MANTAR DERGİSİ (The Journal of Fungus) 10(1), 26-39 (2019). Doi:10.30708mantar.450370. 